\title{
La facultad de teología dentro de una universidad de estudios generales*
}

\author{
Franklin Buitrago Rojas, O. P.**
}

Recibido: 30 de octubre de 2017 • Aprobado: 22 de noviembre de 2017

\section{Resumen}

El modelo universitario de estudio general, con el que se identifica la Universidad Santo Tomás de Colombia, recoge el ideal fundacional de la institución como universitas de conocimiento desde una concepción humanista, que da unidad y coherencia a la labor académica en las diferentes disciplinas y ciencias. La pérdida de ese ideal fundacional de universalidad perjudica no solo la vocación humanizadora del conocimiento sino el lugar de la teología dentro de la universidad como reflexión sobre la totalidad de lo real desde una tradición religiosa. Este artículo muestra cómo el modelo de estudio general busca responder a estas dos dificultades dentro del contexto de una universidad católica.

Palabras clave: estudio general, universidad, teología, facultad, studium generale.

* Este artículo es fruto de la conferencia presentada como Lectio inaugural de las Facultades de Filosofía y Letras y Teología de la Universidad Santo Tomás el día 5 de febrero de 2017. DOI: http://dx.doi.org/10.15332/s2011-9771.2017.0002.01

** Franklin Buitrago Rojas, O. P., fraile dominico. Doctor en Teología y Magíster en Filosofía. Correo electrónico: franklin.buitrago.op@gmail.com 


\title{
The faculty of theology within a university of general studies
}

\begin{abstract}
The university model of general study, which the Santo Tomás de Colombia University identifies with, includes the foundational ideal of the institution as universitas of knowledge from a humanist conception, which gives unity and coherence to the academic labor in the different disciplines and sciences. The loss of that foundational ideal of universality harms not only the humanizing vocation of knowledge but the place of theology within the university as a reflection on the totality of the real from a religious tradition. This article shows how the general study model seeks to respond to these two difficulties within the context of a Catholic university.
\end{abstract}

Keywords: general study, university, theology, faculty, studium generale.

\section{A faculdade de teologia dentro de uma universidade de estúdios gerais}

\section{Resumo}

O modelo universitário de estudo geral, com o qual se identifica a Universidade Santo Tomás da Colômbia, colige o ideal fundacional da instituição como universitas de conhecimento desde uma concepção humanista, que outorga unidade e coerência ao trabalho acadêmico nas diferentes disciplinas e ciências. A perdida desse ideal fundacional de universalidade prejudica não só a vocação humanizadora do conhecimento senão o lugar da teologia dentro da universidade como reflexão sobre a totalidade do real desde uma tradição religiosa. Este artigo mostra como o modelo de estudo geral busca responder a estas duas dificuldades dentro do contexto de uma universidade católica.

Palavras-chave: estudo geral, universidade, teologia, faculdade, studium generale. 


\section{Introducción}

Con frecuencia, los profesores y estudiantes pensamos la misión de nuestra Facultad de Teología de cara a las comunidades religiosas a las que pertenecemos, a las necesidades de la Iglesia o de las Iglesias en Colombia y en Latinoamérica, o de cara a la sociedad civil, pero quiero invitarlos, en esta oportunidad, a reflexionar sobre la misión de nuestra Facultad al interior de nuestra Universidad.

Para quienes les resultó extraño el título de la conferencia, les recuerdo que la Universidad Santo Tomás en su PEI se define a sí misma como una universidad de estudios generales (Universidad Santo Tomás, 2004); de modo que la primera parte de esta Lectio tratará sobre el origen histórico y el sentido de la noción universidad de estudios generales. Luego presentaré algunos puntos sobre las dificultades de la teología como disciplina de estudio dentro de la universidad contemporánea. Y, finalmente, compartiré con ustedes algunas reflexiones sobre el papel de una facultad de teología dentro de una universidad apoyándome en las ideas de dos autores: el dominico holandés Edward Schilebeeckx y el papa emérito Benedicto XVI.

\section{Origen histórico y sentido de la noción universidad de estudios generales}

La Universidad, uno de los productos más destacados de la Edad Media, alcanzó su madurez en el siglo XIII (Buitrago, 2003). En los siglos precedentes, la enseñanza fue más la obra de maestros y grandes personalidades individuales, que de instituciones o colectividades. Con frecuencia, los maestros eran personajes más o menos nómadas que prestaban sus servicios en el espacio de escuelas catedralicias o de escuelas palatinas. Por el contrario, el siglo XIII se caracteriza por un espíritu de asociación: aparecen gremios de comerciantes y artesanos en las nacientes ciudades o burgos y gremios de asociados que defienden sus derechos frente al poder de los señores feudales y de la naciente nobleza urbana.

Dentro de este mismo espíritu nacen gremios de maestros que enseñan diferentes disciplinas, pero que viven junto a sus estudiantes, enseñan en un mismo lugar y obedecen a unos estatutos comunes. Con frecuencia, estos maestros y sus estudiantes provienen de diferentes naciones, pero estudian en común porque hablan una misma lengua franca: el latín. Algunos de estos centros de enseñanza -studium-donde están presentes maestros y estudiantes procedentes de diversas naciones, reciben una carta de derechos del papa o del emperador que los hace 
autónomos frente a las autoridades locales. Estos studium internacionales reciben el adjetivo generalis, que los distingue de los studium particularis de las abadías o de las catedrales.

Se llaman estudios generales por tres razones: porque en ellos se enseñan todas las ciencias del momento, porque reciben profesores y estudiantes de toda la cristiandad, y porque los títulos que otorgan son reconocidos en toda la Europa cristiana. Con el tiempo, los studium generalis comenzarán a llamarse universitas magistrorum et scholarium. Nace así la palabra universitas, más afortunada al designar estos centros; como su nombre lo indica, viene de universo, es decir, expresa la misma idea de generalidad o universalidad: en ella se enseña el universo de todas las ciencias y se reciben maestros y estudiantes de todo el orbe cristiano.

El currículo de un estudiante medieval comenzaba con un ciclo de formación común para todos ellos llamado: "artes liberales", que estaba conformado por dos etapas sucesivas: el trivium y el quatrivium. En el trivium se enseñaban las artes del pensamiento y la comunicación: lógica, retórica y dialéctica. En el quatrivium se enseñaban las artes de la armonía del universo: aritmética, geometría, música y astronomía. Una vez que el estudiante había cursado estas asignaturas, se consideraba que estaba a la altura de la cultura de su tiempo y podía iniciar una especialización. Existían tres especializaciones posibles: la medicina para la salud del cuerpo, la teología para la salud del alma y el derecho para la salud del Estado (Le Goff, 1993).

Años después de su fundación, la Orden de los Dominicos optó por asumir este mismo sistema de estudios para los nuevos frailes que llegaban a ella (Robles, 1968). Fue algo natural, dado que muchos de los primeros dominicos eran maestros y estudiantes provenientes de las nacientes universidades. Los primeros studium generalis de los dominicos, cuya legislación se inspira en los estatutos de la Universidad de París, adquieren todos los rasgos de una corporación universitaria por su apertura a maestros y estudiantes de todo el mundo, por la calidad de su enseñanza y por la agregación oficial a una universidad que les dio carácter público y el derecho a preparar doctores en el campo teológico (Duval, 1967).

Como resultado de esta decisión, en muchas ciudades europeas en las que no había centros universitarios, los conventos que contaban entre sus frailes con un número suficiente de maestros y doctores, abren un studium, no solo para los frailes sino también para los seglares. Con frecuencia, los obispos y los príncipes de regiones que no tenían los medios para crear un studium, patrocinan los conventos dominicanos para que abran al público este tipo de centros de enseñanza. Esta evolución explica en buena medida el talante intelectual que va a caracterizar a la Orden. 
Un proceso semejante se va a replicar en América tres siglos más tarde. Ni la Corona española, ni las jóvenes diócesis americanas cuentan con los recursos económicos o humanos para abrir universidades en sus colonias. Por esta razón, las autoridades civiles y eclesiásticas favorecen a las órdenes religiosas que cuentan con maestros y doctores en sus conventos americanos para que creen nuevos studium generale, donde se puedan formar religiosos y seglares en teología, derecho, medicina y otras áreas necesarias dentro de las colonias.

Este es el origen histórico de la Universidad Santo Tomás y de otras universidades en la América española durante los siglos XVI y XVII. El papa Gregorio XIII autoriza en 1580 que el studium generale del Convento de Santafé de Bogotá se convierta en la Universidad Santo Tomás. Como herederos americanos del modelo educativo europeo, estos studium conventuales y universidades están animados por el mismo espíritu humanista y por la visión integradora de la realidad que caracterizaba a los studium generale medievales (Universidad Santo Tomás, 2004, p. 42).

El desarrollo posterior de la Universidad irá reduciendo este horizonte de universalidad, para dar paso a una creciente especialización en facultades o institutos dirigidos al desempeño profesional. La Universidad irá olvidando gradualmente la base común en la formación que garantizaban las artes liberales y la visión de conjunto frente al universo que le brindaba unidad estructural al studium generale. Tras la Revolución francesa, el espíritu que anima la restauración de las universidades en la era napoleónica, consiste en crear múltiples institutos especializados.

Nace entonces el modelo de facultades independientes y autónomas dentro de una misma universidad y aparecen centros de enseñanza superior especializada como la Escuela Normal o la Escuela Politécnica. Muchas veces, estos institutos especializados funcionan en un mismo espacio físico, pero no tienen ninguna articulación académica entre sí. Este modelo de universidad se difunde también en las universidades de lengua alemana e inglesa.

Paulatinamente se levantan voces de crítica contra este modelo de facultades especializadas, cuando se ven sus efectos negativos y las posibilidades de manipulación que tienen la ciencia y la técnica, al desligarlas de un horizonte humanista y ético. El Romanticismo buscará una nueva unidad del cosmos en el arte, en el mundo de la experiencia interior e, incluso, en el mundo de la experiencia religiosa. Pero, la ciencia seguirá creando compartimentos de la realidad y las universidades seguirán formando profesionales que ven la realidad solo desde el ángulo de una disciplina particular.

¿Cómo responder a esta problemática de la enseñanza universitaria? Algunos autores de mediados del siglo XX plantean la necesidad de recuperar el carácter 
globalizante de la universidad medieval, que se lograba mediante la iniciación de todos los estudiantes en la filosofía y las artes liberales. Es en este contexto, en el que se plantea un modelo universitario de estudios generales, que responde a los planteamientos de instituciones universitarias con una visión humanista (Tunnerman, 1965).

Dentro de una universidad de estudios generales, la especialidad académica de cada facultad se incorpora en la tarea común de toda ciencia y todo conocimiento: contribuir a que el hombre se haga más humano. Con este ideal se creó la Universidad Humboldt de Berlín y se hizo la renovación de las universidades de Míchigan, Oxford y Harvard. En América Latina encontramos este modelo en universidades de Puerto Rico, Colombia, Venezuela, Perú y Chile.

La Universidad de Costa Rica adaptó oficialmente este sistema en 1954 (Castaño, 1968). Cuando se restaura la Universidad Santo Tomás de Bogotá en 1965, los restauradores adoptan el modelo universitario de estudio general. La decisión de la USTA responde en buena medida a dos razones que he expuesto aquí: a sus orígenes históricos y a su orientación humanista cristiana.

\section{La teología en un contexto universitario}

La evolución de las universidades hacia una separación creciente entre ciencias y disciplinas, se desarrolla de manera simultánea con el privilegio concedido por la modernidad a las ciencias exactas y a las disciplinas consideradas útiles para el progreso. Las reflexiones de carácter metafísico, religioso o ético, se ubican en clara desventaja dentro de esta nueva jerarquización de saberes. La teología va quedando relegada o va desapareciendo en muchos ambientes universitarios porque no se adapta a los cánones de la universidad moderna. No se percibe de manera inmediata su utilidad social o su contribución al desarrollo científico y tecnológico.

El teólogo norteamericano David Tracy en su libro Analogical imagination (1998), explica que en algunos lugares las facultades de teología se han ido transformando en "facultades de ciencias religiosas", en un intento por justificar su existencia dentro del contexto de una universidad secular. Las facultades de teología se van convirtiendo así en lugares de estudio del fenómeno religioso desde un punto de vista histórico, sociológico, antropológico o cultural, sin que esto signifique reconocimiento alguno a la validez de la verdad, que dicho fenómeno religioso expresa o desvela.

Los teólogos sabemos bien que el criterio que configura a la teología (al menos en el ámbito cristiano) es la aceptación de la revelación de Dios en la tradición 
bíblica, que tiene su culmen en Jesús de Nazareth. Es por esto que la transformación de la teología en ciencias de la religión, le implica una disolución; un movimiento que no es nuevo, y cuyos orígenes bien pueden remontarse a la teología liberal del siglo XIX.

Otro factor operante en esta disolución de las facultades de teología en facultades de ciencias de la religión, consiste en el prejuicio liberal según el cual, todo discurso creyente debe ser marginado del espacio público porque pertenece al círculo de la vida privada (Taylor, 2007). Siendo las universidades un servicio público y en muchos casos, sustentado directamente por fondos del Estado, se considera que invertir dinero en una reflexión sobre un credo particular, significa ir en contra de los principios del Estado liberal.

En otros casos, el objeto de estudio de dichas facultades, redefinido como hecho religioso, implica lógicamente el reemplazo del estudio de la teología cristiana, por cátedras de estudios islámicos, hindúes y judíos, entre otros, respondiendo a la pluralidad creciente de las sociedades contemporáneas. Esta apertura al estudio de diferentes religiones es buena y procedente, pero es necesario tener claro que, no se trata de teología. El problema aparece cuando se quiere seguir empleando la denominación teología, sobre algo que ya no lo es, provocando una ambigüedad epistemológica.

Como señala Tracy, en reacción a la disolución de la teología dentro de las facultades civiles, muchas Iglesias han optado por retirar a sus estudiantes, los formandos para el ministerio eclesial y a los laicos que buscan una formación explícita dentro de su fe, para reabrir escuelas de teología intraeclesiales. En muchos lugares del mundo, no son pocos los obispos o las autoridades de una comunidad religiosa que han retirado a sus estudiantes de una facultad anteriormente confesional y que han optado por reabrir seminarios y centros de formación intradiocesanos, intracongregacionales o intraeclesiales.

Tracy explica que dicha reacción de parte de las autoridades eclesiales ante la disolución de la teología en las facultades universitarias, representa a la larga, un empobrecimiento para la misma reflexión teológica. Si bien, tal reacción responde a la necesidad comprensible de formar a los ministros eclesiales y a los laicos, en un ambiente donde se reconoce el valor de verdad de la doctrina cristiana, esto limita el espectro de la reflexión y las posibilidades de interpelación de la reflexión teológica. Empobrece a la teología como discurso público.

Una de las grandes revoluciones de la teología en el siglo XIII surgió gracias a su inserción en las nacientes universidades: los maestros de teología entraron en diálogo con los maestros de otras facultades, los estudiantes de teología interactuaban con los estudiantes de medicina, filosofía o derecho; la teología 
adquirió rigor científico y se mantuvo en contacto con las fuerzas vivas de la cultura y de la sociedad. Esta riqueza es la que se puede perder al sacar la teología de la universidad.

¿Qué hacer frente a esta problemática? ¿Cómo mostrar que una facultad de teología es pertinente dentro del conjunto de una universidad, no solamente como el sello institucional necesario cuando la universidad está regentada por una comunidad religiosa o cuando reconoce una identidad confesional? ¿Cómo manifestar que el estudio de la teología tiene algo que decirle al resto de las facultades de una universidad y que no es simplemente el espacio de formación de clérigos, religiosos y pastores? Creo que todo docente o estudiante de teología en una facultad universitaria, más aún los estudiantes laicos, se ha planteado o debería plantearse estas preguntas y, en cierto modo, tomar postura frente a ellas.

Quisiera proponer algunos elementos de respuesta a estas preguntas a partir de ciertas conferencias, dadas por fray Edward Schillebeeckx con ocasión de los 75 años de la Universidad de Friburgo en Suiza, y de un famoso discurso que pronunció su santidad Benedicto XVI en la Universidad de Ratisbona (Alemania), en el año 2006.

\section{La vocación de la Universidad}

En la primera parte, hablando sobre la evolución de la universidad se señaló que las universidades modernas se han ido convirtiendo paulatinamente en una colección de facultades autónomas, que forman profesionales altamente cualificados para desempeñar un oficio dentro de la sociedad o, en concreto, dentro del mercado laboral.

A esta problemática, debe añadirse que los estudios universitarios se han convertido en un asunto de estatus y de movilidad social. Se acude a la universidad y, si se tienen los medios económicos, a ciertas universidades, porque los títulos dados por estas instituciones le abren al estudiante las puertas del mundo laboral y lo ponen en contacto con un medio social y profesional determinado. Esta visión de la universidad como lugar de certificación del estatus social y profesional de las personas, relega muchas veces a un segundo plano los fines auténticos de la misma.

En la competencia aguerrida entre universidades por formar profesionales en un determinado campo, y al interior de cada facultad por mantener su estatus, respondiendo a los estándares de investigación y publicaciones, la universidad ha olvidado su vocación: Ser universitas. Un lugar donde aquellos que se forman 
adquieren una visión universal de la realidad. La universidad no puede olvidar que sus estudiantes se forman no solo para ser especialistas en un campo específico de conocimiento, sino para ser seres humanos, ciudadanos, agentes de cambio con criterios dentro de una sociedad que tiene dimensiones políticas, económicas, culturales, históricas, ecológicas, etc.

Se dice que en el mundo contemporáneo se tienen muchos especialistas, pero pocos sabios; existen profesionales hiperespecializados en un área del conocimiento o en una competencia técnica, pero sin la capacidad de comprender su ejercicio académico o profesional dentro de un todo, dentro de una serie de necesidades y problemáticas más amplias.

Edward Schillebeeckx se pregunta, en esta misma línea, si la universidad no habrá perdido su significado fundamental como factor de cultura y de humanización (1969, p. 429). El conocimiento científico y la técnica son un factor fundamental de la humanización del mundo, pero la universidad tiene una misión más amplia dentro de la sociedad. Debe formar profesionales que, más allá del ángulo psicológico, social, médico, jurídico o sociológico, puedan analizar donde desempeñan su labor, aspectos más profundos y más amplios de la realidad.

Una ciencia es finalmente una parcelización de la realidad con miras a una profundización. Pero esta parcela tiene sentido dentro de un contexto más amplio, desde el conjunto de lo real y de lo humano. Algo que cualquier metafísico entiende pero que muchos científicos parecen haber olvidado cuando quieren absolutizar su ciencia por encima de cualquier consideración humana o ética. La ciencia es una actividad del hombre y para el hombre que solo logra realmente su objetivo cuando aporta a la construcción total de la vida humana en este mundo. De tal modo que las especializaciones académicas no serán verdaderamente humanas, más que cuando se inserten en un conjunto que contribuya a que el hombre se convierta en realmente humano.

En este sentido, Schillebeeckx (1969) explica que nunca será posible llegar a una visión reflexiva exacta de la totalidad original simplemente mediante el diálogo entre los representantes de las ciencias positivas. Aunque las ciencias positivas pretendan un monopolio sobre la palabra ciencia, ellas no agotan ni la totalidad ni la complejidad de lo real, por eso:

No habrá más remedio que apelar a la filosofía, cuyo objeto es precisamente esforzarse en iluminar la totalidad como tal. Una filosofía que tenga por objeto buscar la comprensión de la realidad y de la existencia humana, abierta a escuchar lo que dicen las ciencias y a darle una conexión dentro de una visión más amplia desde la perspectiva de lo 
humano (...). En donde la filosofía y la idea de humanidad dejan de ser el principio estructural, la universidad pierde su razón de ser como universitas y reniega al propio tiempo de su vocación y de su misión propia (p. 434).

El teólogo dominico habla en primer lugar del papel de la filosofía dentro de la universidad. Algo que de por sí no parece comprensible en algunos ambientes científicos; pero que resulta fundamental para los teólogos, porque es precisamente allí donde la teología tiene mucho que aportar, al nivel del sentido de la totalidad de la realidad, al nivel del horizonte de lo humano que le da sentido a toda actividad científica y técnica.

La teología, en efecto, participa junto a las ciencias y la filosofía de ese cuestionarse sobre el sentido de la realidad, de la existencia, de lo humano. Pero, la teología reconoce que ese cuestionarse es posible gracias a que la existencia nos ha sido dada, es un don que trasciende continuamente al hombre y lo invita a trascender. El teólogo reconoce la apertura trascendente del espíritu humano, que le invita a recibir una revelación procedente de una realidad externa a él y mayor que él. La teología en este sentido, se arraiga a una experiencia fundamental de apertura a la trascendencia y postula desde esa experiencia, la validez de una revelación que viene al ser humano.

Dentro de una universidad que se reconoce a sí misma en diálogo y en búsqueda frente al sentido de lo humano y al sentido de la totalidad de la realidad, la teología puede ofrecer respuestas desde la experiencia de acogida existencial e intelectual de la revelación, de ese Dios que es fundamento y origen de la realidad y de lo humano. Como explica Schillebeeckx, se puede rechazar la religión, porque el hombre es libre frente a ella, pero no se puede negar la pertinencia de la teología en esa búsqueda y en ese diálogo. Por eso, a toda universidad, sea laica o confesional, le debería interesar la pregunta sobre Dios. Le debería interesar lo que la experiencia religiosa pone de manifiesto sobre el sentido del mundo y del ser humano.

No plantear la pregunta por Dios sería excluir un tema fundamental de la realidad humana y, en cierto modo, un menosprecio contra la razón, pues se estaría asumiendo que esta no es capaz de plantearse la cuestión de su propio fundamento. Temas como la existencia de Dios, el fin último del hombre o el fundamento de la moral, son asuntos que todas las personas se plantean en un momento u otro (Tracy, 1998) y que merecen ser abordados racionalmente.

Además de lo planteado por Schillebeeckx, la marginación de la teología conlleva a un empobrecimiento de las universidades en varios sentidos. Hoy en 
muchos espacios se cuestiona el secularismo entendido como expulsión de lo religioso de los espacios públicos. Aparecen nuevas posibilidades de integración de lo religioso dentro del campo social, comunitario, religioso y educativo. En esto, por ejemplo, ha sido de gran valor la obra del filósofo canadiense Charles Taylor (Taylor, 2007). En diferentes países europeos, muchas personas se plantean serias preguntas frente a la preponderancia que toma el islam, mientras que Europa parece alejada o incluso avergonzada de sus raíces cristianas.

El problema no es solo de identidad cultural o del regreso de un conservadurismo xenófobo, sino de los efectos de una reclusión artificial de lo religioso al ámbito de lo privado, que termina por empobrecer y reducir los lenguajes comunes que permiten plantear de modo razonable, las preguntas fundamentales sobre la existencia, el sentido de la vida, la relación con el otro y con el cosmos (Habermas, 2001).

Otro elemento interesante que Schillebeeckx subraya, y que se encuentra en profunda sintonía con la identidad tomista de esta facultad, es la interacción necesaria de la teología con la filosofía y las ciencias. No se trata de argumentar directamente desde el dato revelado o del texto bíblico, queriendo convencer o contradecir al científico o queriendo orientar al que maneja un saber técnico. Esos saltos de lenguaje y de episteme terminan con frecuencia en contrasentidos. Schillebeeckx reconoce la necesidad de una mediación por parte de la filosofía y específicamente, de una filosofía que se pregunte sobre el sentido de la realidad y el sentido de la existencia humana. Sobre ese terreno y a ese nivel, el teólogo y el científico pueden sentarse a conversar.

En este contexto de diálogo sobre cosmovisiones mediado por la filosofía, Schillebeeckx explica que una universidad, concretamente una universidad católica, debe contar con un espacio de reflexión teológica donde se pueda articular la visión católica de la vida, confrontándola a un nivel académico con la cultura de la época y sus problemas (1969, p. 426). Este espacio de reflexión teológica debe ser el corazón y el alma de la universitas catholica, porque es allí donde adquieren una dimensión humana integral y una dimensión cristiana, de los trabajos especializados de las diversas facultades.

\section{La teología dentro de la universidad católica}

La constitución Ex Corde Ecclessiae también ubica el rol de la teología dentro de una universidad católica en el campo del diálogo entre fe y razón, entre fe y cultura (Juan Pablo II, 1990). La enseñanza y la investigación de la teología 
contribuyen dentro la universidad, a promover la dignidad humana de modo riguroso y crítico. La teología está llamada a escrutar la realidad en su profundidad y en su totalidad, distinguiéndose por su libre búsqueda de toda la verdad acerca de la naturaleza, del hombre y de Dios. La teología, como la filosofía o la literatura, puede hacer preguntas que el método científico no se hace sobre las implicaciones del conocimiento y la técnica a nivel de lo humano, y más allá, frente al fundamento mismo de la realidad.

El rol evangelizador de la teología dentro de la universidad, respetando la fisonomía de la institución, consiste en mostrar la pertinencia que tiene el mensaje cristiano frente al mundo, la sociedad, las ciencias y la cultura, con una palabra que interpele, que plantee preguntas y ofrezca posibilidades de respuesta en los lenguajes propios de una tradición religiosa y teológica, en palabras de la constitución, esto significa permitir que la evangelización de la cultura sea real y no una ideología.

En este mismo sentido, es interesante la afirmación de Schillebeeckx sobre que, la reflexión teológica está al servicio de la libertad personal de los estudiantes. A veces, se tiene el prejuicio de que si una universidad manifiesta una visión particular de la vida, esto genera dogmatismos y estrechez de visión para el trabajo intelectual. Por el contrario, para Schillebeeckx, cuando las visiones de la vida que animan el trabajo académico quedan sin decir y sin articular, estas permanecen como supuestos callados, muchas veces ideológicos, sin posibilidad de expresión ni articulación.

Las visiones de la vida, las convicciones que mueven la acción, se forman en una comunidad de diálogo y el hecho que sean afirmadas de modo explícito en un espacio de reflexión dentro de la universitas, le permite al estudiante plantearse preguntas, elaborar sus respuestas y tomar postura ante los temas esenciales de la existencia. Por eso, la existencia de una facultad de teología católica dentro de una universidad no implica que todos los profesores y estudiantes estén necesariamente de acuerdo sobre la cosmovisión de fondo. Al contrario, la exposición articulada de una cosmovisión ayuda al interlocutor a modular su propia cosmovisión subyacente reconociendo elementos en los que se reconoce y elementos en los que no se reconoce.

Del mismo modo, Schillebeeckx señala que todo el trabajo científico y toda la técnica están fundadas en una esperanza: la esperanza en que el mundo se puede mejorar a partir de la actividad humana. La ciencia es una dimensión del hombre que despliega su libertad en el orbe como un proyecto y una esperanza de futuro. También el cristiano espera algo para el mundo y para su historia humana. Pero 
para él, el mundo posee un sentido que no es solamente mundano: un sentido que no posee por sí mismo y que se debe asignar en razón de la responsabilidad que Dios ha confiado a los creyentes.

Por esta misma razón, para la teología es de suma importancia existir como una facultad entre las otras facultades de la universidad, porque son estas las que le proporcionan su problemática. Afirma Schillebeeckx:

Una simple escuela superior de teología se encontraría necesariamente en una situación precaria. La teología no puede desarrollarse plenamente más que dentro de una universitas scientiarum, cuya misma estructura es la que permitirá un enriquecimiento recíproco (...). El teólogo que pierda contacto con el desarrollo de las ciencias, será fatalmente incapaz de interpretar cristianamente la secularidad actual, por ejemplo, y la dimensión nueva que adquiere en nuestros días la vida humana en virtud del papel cada vez más importante de la ciencia (p. 441).

Una idea semejante de lo que debe ser la universidad y la teología dentro de ella, la expresó el papa Benedicto XVI en el discurso pronunciado en el año 2006, cuando visitó su alma mater, la Universidad de Ratisbona. Hablando de sus años de universidad, se refería el papa a la

Experiencia de universitas, es decir, la experiencia de que, no obstante todas las especializaciones que a veces nos impiden comunicarnos entre nosotros, formamos un todo y trabajamos en el todo de la única razón con sus diferentes dimensiones, colaborando así también en la común responsabilidad respecto al recto uso de la razón (Benedicto XVI, 2006).

En ese mismo discurso, que tuvo gran resonancia mediática por las referencias al islam y la violencia, el papa Ratzinger recordaba que el teólogo católico encuentra naturalmente su lugar dentro de la universidad gracias a la

Convicción de una armonía profunda entre el Logos que se revela en la Palabra, ese Dios creador que se revela en la historia, y el Logos como principio unificador y explicador de la realidad que los filósofos helenísticos buscaban más allá de las ciencias particulares. Es la dinámica de encuentro entre fe y razón que siempre ha acompañado la teología cristiana y que le da una vocación de diálogo en pos de la universitas, de la universalidad del conocimiento (2006). 
Resulta interesante que, en ese mismo discurso, Benedicto XVI recordó que el diálogo entre cristianismo y filosofía, entre teología y cultura, es algo natural para la Iglesia católica porque esta reconoce la analogía entre Dios y nosotros, entre su eterno Espíritu creador y nuestra razón creada. Esta afirmación doctrinal de la Iglesia fue definida dogmáticamente en el IV Concilio de Letrán, celebrado en 1215, frente a las herejías cátaras que en el sur de Francia reactualizaban las ideas maniqueas de separación radical entre la esfera de lo divino y el mundo material visible.

En este concilio se encuentra presente Domingo de Guzmán, el fundador de la Orden de los Dominicos, comunidad religiosa que asumiría unas décadas más tarde la estructura del studium generale y las artes liberales, como formación básica para todos sus frailes. Las referencias históricas llevan una vez más al siglo XIII, siglo del nacimiento de las universidades, del nacimiento de las Ordenes Mendicantes y de la aparición de las grandes sumas de teología que integran la filosofía, los conocimientos científicos de la época y la teología, gracias a una visión unitaria de la realidad.

\section{Conclusión: la Facultad de Teología en la USTA}

Es sabido que, dentro de la Universidad Santo Tomás, el espacio de interpelación y de reflexión en torno a lo humano y las visiones del mundo, se ofrece a todos los estudiantes desde las cátedras del Departamento de Humanidades y que llegan a todas las facultades de la Universidad. Quienes hemos tenido la oportunidad de ser docentes de dichas cátedras, sabemos que no siempre es fácil que estudiantes y docentes de otras facultades perciban la razón de ser de una cátedra de antropología, ética o cultura teológica dentro de su currículo.

Para un diálogo interdisciplinario se necesita de interlocutores, de docentes y estudiantes de otras facultades, dispuestos a entablar un diálogo sobre las concepciones de la vida, las visiones del mundo y del ser humano que están a la base de su trabajo académico y de su ejercicio profesional. Muchas veces los profesores de estas cátedras de humanidades necesitan moverse como "anfibios académicos" para hablarles de antropología o de teología a ingenieros, comunicadores sociales o diseñadores gráficos.

Sin embargo, a pesar de las dificultades y desafíos, dichas cátedras son un espacio privilegiado, un espacio trasversal que llega a todas las facultades. Por eso, la reflexión interdisciplinaria que estas cátedras promueven necesita ser 
alimentada y suscitada a partir del núcleo del estudio general que lo constituyen las facultades de Filosofía y Teología.

Creo que ese es un lugar que la Facultad de Teología, de modo particular, debe ocupar cada vez con mayor claridad dentro de nuestra Universidad. Cuando pensamos en la proyección social de la Facultad de Teología la pensamos de cara al servicio que le prestamos a la Iglesia, a las comunidades eclesiales, en la formación de laicos, religiosos y pastores, a la respuesta que damos a grupos marginados de nuestra sociedad desde nuestra reflexión teológica.

Pero quisiera invitar a pensar también la proyección de nuestra Facultad de cara a la Universidad, a reconocer nuestra misión como lugar de reflexión dentro de un estudio general. Estudiar y enseñar teología dentro de una universidad que tiene una variedad de facultades y campos de saber no es lo mismo, o no debe ser lo mismo, que estudiar teología en un seminario diocesano o en una escuela intraeclesial. Estudiar y enseñar teología en una universidad donde los estudiantes de todas las facultades cursan cátedras humanistas como sello distintivo de sus opciones pedagógicas es una gran oportunidad. Esa misión universitaria, misión de diálogo con las ciencias y con la cultura, debería ser una prioridad también en nuestras líneas de investigación, en nuestras publicaciones y en los eventos académicos que desde aquí se proponen.

\section{Referencias}

BenedictoXVI. (2006). Fe, razón y universidad. Recuerdos y reflexiones. Recuperado de: https://w2.vatican.va/content/benedict-xvi/es/speeches/2006/september/ documents/hf_ben-xvi_spe_20060912_university-regensburg.html (Consultado el 23 de febrero de 2017).

Buitrago Rojas, F. (2003). El Studium Generale: un lugar de encuentro entre la Revelación y las ciencias del hombre. Optantes, 12(24).

Castaño, J. (1968). De la diversidad a la universidad: studium generale. Ponencia presentada en el Congreso Latinoamericano de Estudios Generales. Bogotá, Colombia.

Duval, A. (1967). L'étude dans la legislation religieuse de Saint Dominique. En Mélanges offerts a M.D. Chenu. Bibliotéque thomiste 37. Paris.

Habermas, J. (2001). La comunicabilidad de las afirmaciones de una tradición y de una comunidad creyente. En El poder de la religión en la esfera pública. Madrid, España: Trotta.

Juan Pablo II. (1990). Ex Corde Ecclessiae. Constitución apostólica del sumo pontífice Juan Pablo II sobre las universidades católicas. Recuperado de: http:// 
w2.vatican.va/content/john-paul-ii/es/apost_constitutions/documents/hf_jpii_apc_15081990_ex-corde-ecclesiae.html

Le Goff, J. (1993). Los intelectuales en la Edad Media. Barcelona, España: Gedisa.

Robles, L. (1968). El estudio de las “artes liberales” en la primitiva legislación dominicana. Antecedentes históricos. Studium, 8, 61-85.

Schillebeeckx, E. (1969). El mundo y la Iglesia. Salamanca, España: Ediciones Sígueme.

Taylor, C. (2007). A secular Age. Cambridge, MA: Harvard University Press.

Tracy, D. (1998). Analogical imagination. Christian Theology and the Culture of Pluralism. New York, NY: Crossroad Publishing.

Tunnerman, C. (1965). Exégesis de los estudios generales. V reunión de la Comisión Centroamericana Pro-Estudios Generales. Bogotá D. C., Universidad de los Andes.

Universidad Santo Tomás (2004). Proyecto Educativo Institucional (PEI). Bogotá D. C., Colombia: Ediciones USTA. 